\title{
La conización por láser y el "LEEP" aumentan el riesgo de parto pretérmino por rotura prematura de membranas
}

\section{Objetivo}

Estimar el riesgo de tener un parto pretérmino en mujeres que tienen el antecedente de una ablación/conización con láser, o un LEEP (sigla en inglés de "Procedimiento de Escisión Electro-quirúrgica por Lazo") por haber presentado una neoplasia intraepitelial cervical.

\section{Diseño}

Cohorte retrospectiva. ${ }^{*}$

\section{Lugar}

Nueva Zelanda, Auckland, National Women`s Hospital.

\section{Pacientes}

Mujeres que hayan concurrido al servicio de colposcopía del hospital entre los años 1988 y 1999, y que hayan tenido un parto en el mismo hospital entre los años 1989 y 2000.

\section{Evaluación de factores pronósticos}

El grupo expuesto corresponde a aquellas mujeres que fueron tratadas por patología cervical antes del embarazo, y que realizaron ablación/conización por láser o LEEP. El grupo no expuesto corresponde a aquellas que no requirieron tratamiento cervical. Fueron excluidas mujeres con antecedentes de tratamientos cervicales previos.

\section{Medición de resultados principales}

Se evaluó la tasa global de parto pretérmino ( $<37$ semanas), y se la dividió en parto pretérmino espontáneo, parto pretérmino como consecuencia de rotura prematura de membranas (RPM), y parto pretérmino iatrogénico (por otras causas). Los resultados fueron ajustados* por edad, tabaquismo, etnia, antecedentes de parto pretérmino y traslado desde otro centro.

También se analizó el efecto de la cantidad de tratamientos cervicales realizados, así como la altura del cono resecado.

Fuente de financiamiento: National Insitute of Child Health and Human Devlopment.

\section{Resultados principales}

Las mujeres sin tratamientos previos fueron 426, y 652 las que habían recibido alguno. La tasa global de partp pretérmino fue del $13,8 \%$, la de RPM de $6,2 \%$ y la de parto pretérmino espontáneo de $3,8 \%$. La probabilidad de que ocurra una RPM de pretérmino fue casi el doble en las mujeres tratadas que en las que no tuvieron tratamiento (ver tabla 1). El único factor pronóstico que mostró un riesgo aumentado de parto pretérmino fue una altura de resección del cono que supere $1,7 \mathrm{~cm}$. También se observó una asociación entre la altura del cono y el riesgo de RPM (ver tabla 2).

Tabla 1. Riesgo Relativo de parto pretérmino y RPM según el tratamiento cervical realizado

\begin{tabular}{l|c|c|c|c|c} 
& $\begin{array}{c}\text { Sin } \\
\text { tratamiento }\end{array}$ & $\begin{array}{c}\text { Gualquier } \\
\text { tratamiento }\end{array}$ & $\begin{array}{c}\text { Conización por } \\
\text { láser }\end{array}$ & LEEP & $\begin{array}{c}\text { Ablación por } \\
\text { láser }\end{array}$ \\
\hline Parto pretérmino & 1 & $1,1(0,8-1,5)$ & $1,3(0,8-2,2)$ & $1,3(0,8-2,2)$ & $0,8(0,5-1,2)$ \\
\hline $\mathbf{R P M}$ pretérmino & 1 & $1,8(1,0-3,2) \#$ & $2,7(1,3-5,6) \#$ & $2,7(1,3-5,6) \#$ & $1,1(0,5-2,4)$ \\
\hline
\end{tabular}

Se reportan RR ajustados* (IC95\%), utilizando como basal al grupo sin tratamiento. \# $p<0,05$

Tabla 2. RR de parto pretérmino y RPM según la altura del cono cervical

\begin{tabular}{c|c|c|c|c} 
& \multirow{2}{*}{$\begin{array}{c}\text { Sin } \\
\text { tratamiento }\end{array}$} & \multicolumn{3}{|c}{ Altura del cono cervical } \\
\cline { 3 - 5 } & $\mathbf{0 , 1 - 1 , 0} \mathbf{~} m$ & $\mathbf{1 , 1 - 1 , 6} \mathbf{~ m m}$ & $\geq \mathbf{1 , 7} \mathbf{~ m m}$ \\
\hline Parto pretérmino & 1 & $0,9(0,5-1,6)$ & $1,1(0,6-1,9)$ & $1,7(1,0-2,7)$ \\
\hline $\mathbf{R P M}$ pretérmino & 1 & $1,1(0,4-3,0)$ & $1,7(0,7-4,0)$ & $3,6(1,8-7,5) \#$ \\
\hline
\end{tabular}

Se reportan RR ajustados* (IC95\%), utilizando como basal al grupo sin tratamiento. \# $p<0,05$

\section{Conclusiones}

Las mujeres con antecedentes de conización por láser o LEEP tienen riesgo aumentado de parto pretérmino por RPM. La altura del cono es un factor de riesgo de parto pretérmino. La tasa de parto pretérmino global no se asoció a ninguno de los tratamientos evaluados.

\section{Comentario}

Muchos autores sugieren que existe asociación entre el antecedente de un tratamiento cervical y el riesgo de un parto pretérmino subsiguiente. ${ }^{1-3}$ Sin embargo, pueden observarse limitaciones metodológicas en muchos de los estudios previos. Además, el advenimiento de técnicas como LEEP o la utilización del láser han hecho necesaria la reevaluación de este tema. En el presente estudio pueden considerarse dos importantes fortalezas: el análisis de una cohorte de mujeres con y sin tratamiento; y el adecuado tamaño muestral.

Se puede observar una asociación entre el tratamiento cervical y la probabilidad de RPM en un embarazo posterior. Si bien los resultados obtenidos han sido ajustados por múltiples variables, hubiera sido interesante también evaluar la vaginosis bacteriana y las anomalías uterinas (reconocidos factores de riesgo), pero esto no pudo llevarse a cabo por tratarse de un estudio retrospectivo.

En cuanto a la importancia clínica de los resultados, cabe resaltar que se consideró parto pretérmino cuando ocurría antes de las 37 semanas. Aunque esto es adecuado, las principales complicaciones de la prematurez se asocian a edades gestacionales menores a las 32 o 34 semanas, por lo que sería importante evaluar si las diferencias encontradas en este estudio persisten cuando esa edad gestacional se utiliza como punto de corte.

En cuanto a la validez externa*, conviene señalar que todos los procedimientos fueron realizados en un centro especializado de patología cervical. Dado que este tratamiento podría tener menor tasa de complicaciones en manos experimentadas que en aquellas que no lo están, este factor debe tenerse en cuenta a la hora de aplicar estos resultados en nuestro medio.

Por otro lado, se puede observar consistencia de estos hallazgos con los encontrados por otros autores, ya que en una revisión sistemática se observó asociación entre la utilización de LEEP y el parto prematuro. ${ }^{4}$

\section{Conclusiones del comentador}

Se sugiere identificar a aquellas mujeres con antecedentes de tratamiento de patología cervical para informar su riesgo de parto prematuro, y brindar las pertinentes pautas de alarma.

\section{Dr. Demián Glujovsky [ Fellow en Reproducción Humana, IFER, Instituto de Ginecología y Fertilidad. ]}

2004;7:169. Comentado de: Treatment for cervical intraepithelial neoplasia and risk of preterm delivery. Sadler L, Saftlas A, Wang W y col. JAMA. 2004 May 5; $291: 2100-6$

\section{Referencias}

1. Hagen B, Skjeldestad FE. Br J. The outcome of pregnancy after CO2 laser conisation of the cervix. Obstet Gynaecol. 1993; 100:717-20.

2.Delivery outcomes following loop electrosurgical excision procedure for microinvasive (FIGO stage IA1) cervical cancer. Gynecol Oncol. 2002; 86:10-3.

3.Svare JA, Anderson LF, Langhoff-Roos J et al. The relationship between prior cervical conization, cervical microbial colonization and preterm premature rupture of the membranes. Eur J Obstet Gynecol Reprod Biol. 1992; 47:41-5.

4.Crane JM. Pregnancy outcome after loop electrosurgical excision procedure: a systematic review. Obstet Gynecol. 2003 Nov; 102:1058-62. 